\title{
Craniofacial dyssynostosis
}

INSERM

\section{Source}

INSERM. (1999). Orphanet: an online rare disease and orphan drug data base.

Craniofacial dyssynostosis. ORPHA:1516

Craniofacial dyssynostosis (CFD) is a rare cranial malformation syndrome characterized by the premature closure of both lambdoid sutures and the posterior sagittal suture, resulting in abnormal skull contour (frontal bossing, anterior turricephaly with mild brachycephaly, biparietal narrowing, occipital concavity) and dysmorphic facial features (low-set ears, midfacial hypoplasia). Short stature, developmental delay, epilepsy, and oculomotor dyspraxia have also been reported. Associated anomalies include enlargement of the cerebral ventricles, agenesis of the corpus callosum, Arnold-Chiari malformation type I (see this term), venous anomalies of skull and hydrocephalus. 